\title{
Pavement Rehabilitation using Cold Mix Technology
}

\author{
Abhijith A \\ Department of Civil Engineering \\ Mar Baselios College of Engineering \& Technology \\ Trivandrum, India
}

\author{
Govind A \\ Department of Civil Engineering \\ Mar Baselios College of Engineering \& Technology \\ Trivandrum, India
}

\author{
Shahin M B \\ Department of Civil Engineering \\ Mar Baselios College of Engineering \& Technology \\ Trivandrum, India
}

\begin{abstract}
The increase in environmental pollution due to the vast fuel consumption in hot mix technology during road construction leads to various harmful effects on environment and human health. For improving this situation, adopting the cold mix technology over hot mix technology in road construction is a considerable solution. This project was done to analyse the performance of Bitumen Stabilised Material of varying bitumen content by indirect tensile strength. The performance of lime as filler is analysed. Using $80 \%$ Recycled Asphalt pavement (RAP), $20 \%$ virgin material, water and binder with varying proportions of lime, samples were casted and tests were done. Level $1 \mathrm{mix}$ design for casting the samples was done as per the South African mix design procedure. The important tests conducted were Marshall Stability Analysis test and Indirect Tensile Strength test.
\end{abstract}

Index Terms:- Cold Mix Technology, Emulsion, Pavement Rehabilitation, Green Roads, Pavement Recycling

\section{INTRODUCTION}

A flexible pavement structure is typically composed of several layers of material. Each layer receives the loads from the above layer, spreads them out, and then passes these loads to the next layer below. Different layers in a flexible pavement include wearing course, binder course, base course, sub base and a proctor compacted layer at the bottom. The wearing and binder course together forms the surface course, which comes in contact with the traffic. Base course generally consists of aggregates. The conventional technique of pavement construction in India is carried out using hot mix asphalt (HMA). HMA pavements are classified as "flexible" pavements because the total pavement structure deflects, or flexes, under loading. Another technique named warm mix asphalt (WMA) has received considerable attention which consumed lesser energy than HMA in the past few years and lesser pollutant emissions unlike that during hot mix asphalt production and placement. Also, studies revealed that the WMA mixtures had higher indirect tensile strength (ITS) than the HMA and thus concluded that warm mix asphalt technology can be a better option as compared to the HMA in term of its environmental benefits (Izadi and Mirzaiyan, 2016).

Again, to decrease the energy consumption and release of pollutants during the construction of pavements, a better technology which did not involve any heating procedures was developed, namely cold in-place recycling (CIR). CIR is the processing and treatment with bituminous and/or chemical additives of existing HMA pavements without heating to produce a restored pavement layer. This efficiently improves the road surface and strength while minimizing expenses typically incurred during the paving process. CIR is carried out using reclaimed asphalt pavement (RAP) as the aggregate. RAP is the term given to removed and/or reprocessed pavement materials containing asphalt and aggregates. When properly crushed and screened, RAP consists of high-quality, well-graded aggregates coated by asphalt cement, which is a refined asphalt form free from water and coarse foreign material.

With increased demand and limited aggregate and binder supply RAP is a valuable component in HMA. As a result, there has been interest in increasing the amount of RAP used in HMA. The primary objective is to encourage the use of recycled materials in the construction of highways to the maximum economical and practical extent possible with equal or improved performance. While a number of factors drive the use of RAP in asphalt pavements, two primary factors are economic savings and environmental benefits. RAP is useful alternative to fresh materials because it reduces the use of virgin aggregate and the amount of virgin asphalt binder required in the production of not only HMA but for cold mixes also.

It is extremely important to maintain stipulated temperatures at the time of producing the mix, laying and compaction in case of hot mix asphaltic pavements. It is difficult to maintain such temperature requirements in high rainfall areas, high altitude, winter conditions, and long transit distance. These challenges can be overcome using cold mix technology. Cold mix when used as paving mix can offer advantages such as energy savings and overall reduced cost as compared to typical hot mix, easy preparation, environmental friendly and 
conservation of energy, etc. CIR can correct deep asphalt defects such as rutting, fatigue (alligator) cracking, and utility cuts that cannot be addressed by a surface treatment or an overlay, and allows minor corrections to the profile of a road surface, reduces reflective cracking, and results in a minor inconvenience to traffic. CIR with the new-engineered emulsions or foamed asphalt technology also gives greater resistance to reflective and thermal cracking. From public roadways to airport runways, its performance has been tested and proven. (Forsberg et al., 2014)

Failure on pavements is classified into structural failure and functional failure. In case of functional failure simple overlay maybe sufficient but in case of structural failure, reconstruction of pavement is the only solution because simple overlay results in reflection cracking. For rehabilitation to be economical, partial depth reclamation can be adopted in comparison with full depth reclamation. In partial depth reclamation, layers till base course are reclaimed. Rehabilitation also helps in limiting the pavement thickness, enabling maintenance of underlying utilities like drainage, underlying pipelines, manholes, etc. easier.

\section{METHODOLOGY}

For preparation of cold mixes, bituminous stabilised mixes (BSM), type of aggregate grading as per South African Technical guideline - TG2 has been considered. BSM samples are prepared in room temperature. These samples were cured at $40^{\circ} \mathrm{C}$ for a day, followed by dry/wet curing conditions for $3 / 5$ days. Indirect testing was done in dry and wet conditioned marshal specimens.

Wet sieve analysis was conducted to determine the gradation of RAP (Fig.1). Gradation affects many properties of an aggregate. It affects bulk density, physical stability and permeability. With careful selection of the gradation, it is possible to achieve high bulk density, high physical stability, and low permeability.

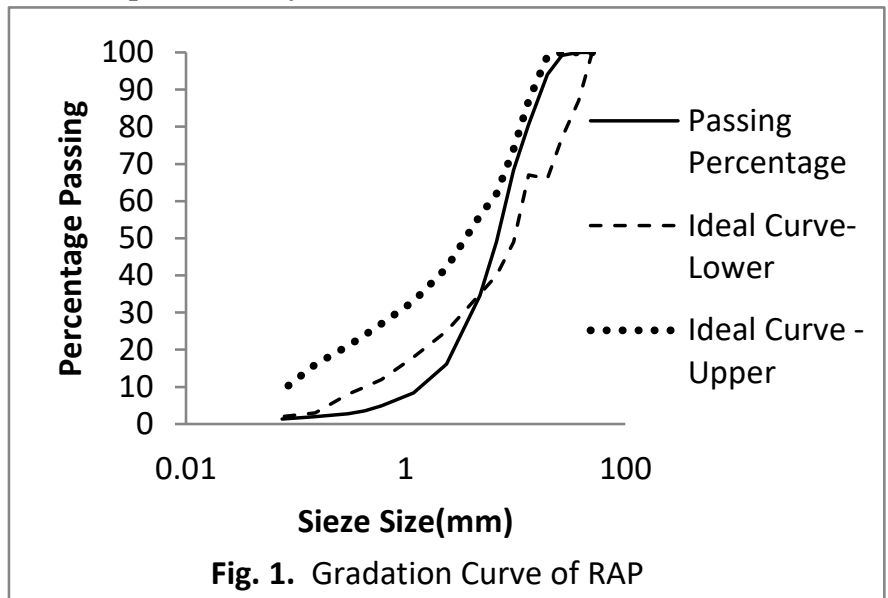

To determine natural water content on RAP, Oven drying is used. Aggregates having higher water content are more porous in nature and are generally considered unsuitable unless they are found to be acceptable based on strength, impact and hardness tests. It was observed that the average Moisture Content of RAP is $0.794 \%$.

To determine optimum moisture content and maximum dry density in RAP, Proctor test was carried out. Seven trials were done and the results are obtained as shown in Fig. 2

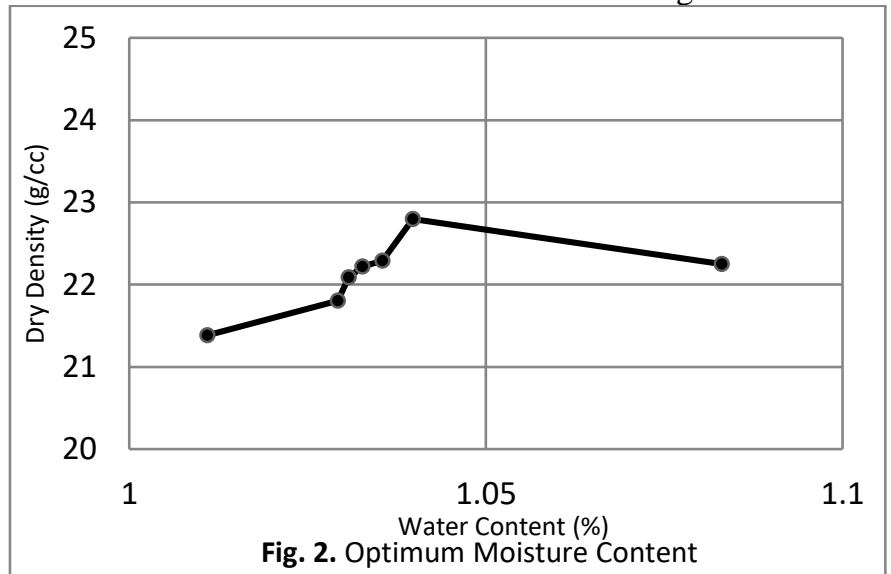

Optimum Moisture Content of the collected RAP is $1.04 \%$ and corresponding Maximum Dry density is $22.79 \mathrm{~g} / \mathrm{cc}$.

Asphalt content was determined by ignition method by removing the asphalt cement in an ignition furnace. The asphalt content was calculated by difference from the mass of the residual aggregate and moisture content. The asphalt content is expressed as mass percent of moisture-free mixtures. The asphalt content obtained was $3.91 \%$.

Experiment was conducted for extraction of aggregates in pavement samples, using benzene by centrifugal process. Aggregates were extracted from the RAP sample and Percentage binder was found to be $5.125 \%$. This was mainly done to extract aggregates from the RAP.

Impact test was conducted on the extracted aggregates and it was found to be $16.424 \%$ and we inferred that material is exceptionally tough/strong.

Experiment was conducted to determine the specific gravity and water absorption of extracted Aggregate. Extracted coarse aggregate greater than $10 \mathrm{~mm}$ has specific gravity of 2.73 and the value is optimum for road construction, but for extracted aggregates which is having less than $10 \mathrm{~mm}$ specific gravity is outside the optimum range, its mainly due to the centrifugal extraction.

After characterizing the RAP, it was decided to use $80 \%$ RAP, 16/18 \% stone dust and 4/2\% lime along with $53.55 \mathrm{gm}$ water and $35.7 \mathrm{gm}$ emulsion to make Bitumen Stabilized Mixes(BSM). Twenty eight samples were casted for each emulsion (ie; EM 1, EM 2, EM3, EM 4), thus making a total of 96 samples. Out of each emulsion sample, 12 samples were casted with $2 \%$ lime and 12 with $4 \%$ lime. Further 6 out of these 12 samples were given 3 days curing and 6 samples were given 5 days curing. Out of this 6,3 samples were given dry curing and 3 were given wet curing. 


\section{Indirect Tensile Strength}

All these samples were tested for Indirect Tensile Strength(ITS), using ITS apparatus .It is an experimental method developed to understand and evaluate creep properties as well as strength of bituminous mixes. It is the indirect measure of the tensile strength and flexural characteristics of the BSM. Breaking stress of the specimen is found out by applying monotonic load to cylindrical specimens. The specimen having $100 \mathrm{~mm}$ diameter and $60 \mathrm{~mm}$ thickness is used. The load is applied at $50 \mathrm{~mm} / \mathrm{min}$.

The specimen was removed from the air for ITS dry \& water bath for ITS wet and placed into the lower loading strip of loading apparatus. Slowly the top loading strip was made light contact with the specimen and ensured that the loading strips are parallel and centered on the vertical diametric plane. A vertical compressive ramp load was given until the maximum load is reached and the load is recorded as the maximum load. The elapsed time between removal of test specimens from the bath and the final load determination was kept within 2 minutes.

$$
\text { IDT strength, } \mathrm{S}_{\mathrm{t}}=\frac{2000 \times P}{\pi \times t \times D}
$$

where:

$$
\begin{aligned}
& S_{t}=\text { IDT strength, } \mathrm{kPa} P=\text { maximum load, } \mathrm{N} \\
& t=\text { specimen height immediately before test, } \\
& \mathrm{mm} \\
& D=\text { specimen diameter, } \mathrm{mm}
\end{aligned}
$$

\begin{tabular}{|c|c|c|c|}
\hline Emulsion & $\begin{array}{c}\text { Lime } \\
\text { content }\end{array}$ & Sample & $\begin{array}{c}\text { Average Indirect } \\
\text { Tensile Strength } \\
\left(\mathrm{N} / \mathbf{m m}^{2}\right)\end{array}$ \\
\hline \multirow{8}{*}{ EM 01} & \multirow{4}{*}{$2 \%$} & 3 DAY DRY & 373.21 \\
\hline & & 3 DAY WET & 453.67 \\
\hline & & 5 DAY DRY & 421.10 \\
\hline & & 5 DAY WET & 486.83 \\
\hline & \multirow{4}{*}{$4 \%$} & 3 DAY DRY & 340.74 \\
\hline & & 3 DAY WET & 386.54 \\
\hline & & 5 DAY DRY & 340.74 \\
\hline & & 5 DAY WET & 386.54 \\
\hline \multirow{8}{*}{ EM 02} & \multirow{4}{*}{$2 \%$} & 3 DAY DRY & 311.44 \\
\hline & & 3 DAY WET & 391.24 \\
\hline & & 5 DAY DRY & 378.27 \\
\hline & & 5 DAY WET & 474.65 \\
\hline & \multirow{4}{*}{$4 \%$} & 3 DAY DRY & 328.65 \\
\hline & & 3 DAY WET & 408.54 \\
\hline & & 5 DAY DRY & 483.75 \\
\hline & & 5 DAY WET & 481.46 \\
\hline \multirow{8}{*}{ EM 03} & \multirow{4}{*}{$2 \%$} & 3 DAY DRY & 311.26 \\
\hline & & 3 DAY WET & 403.25 \\
\hline & & 5 DAY DRY & 384.33 \\
\hline & & 5 DAY WET & 391.56 \\
\hline & \multirow{4}{*}{$4 \%$} & 3 DAY DRY & 361.42 \\
\hline & & 3 DAY WET & 357.37 \\
\hline & & 5 DAY DRY & 402.88 \\
\hline & & 5 DAY WET & 495.76 \\
\hline \multirow{8}{*}{ EM 04} & \multirow{4}{*}{$2 \%$} & 3 DAY DRY & 335.73 \\
\hline & & 3 DAY WET & 364.33 \\
\hline & & 5 DAY DRY & 384.33 \\
\hline & & 5 DAY WET & 391.56 \\
\hline & \multirow{4}{*}{$4 \%$} & 3 DAY DRY & 354.41 \\
\hline & & 3 DAY WET & 498.86 \\
\hline & & 5 DAY DRY & 440.68 \\
\hline & & 5 DAY WET & 479.20 \\
\hline
\end{tabular}

\section{RESULTS}

Table 1. Indirect Tensile Strength
Analysis of Indirect Tensile Strength (ITS)

ITS of the Marshall specimens of emulsions having different binder content is analyzed. The emulsion in each specimen is $3.4 \%$ of total weight. From the Fig. 3, it is seen that all the emulsions showed ITS value greater than $225 \mathrm{kPa}$ and confirm to BSM 1, which is having high shear strength and can be used as a base layer for design traffic applications of more than 6 million equivalent standard axles (MESA).

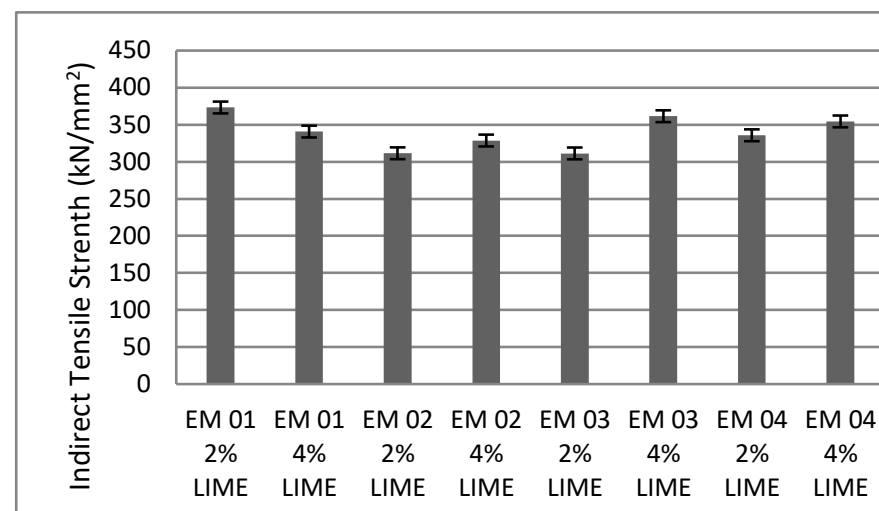

Fig. 3. Average indirect tensile strength of emulsions

Curing was done at $40^{\circ} \mathrm{C}$ sealed condition for 3 days and 5 days and ITS testing was done. Curing affect the stiffness and attainment of strength. As the curing time increases, ITS value increase as the binder-filler mortar material stabilizing the mix hardens thereby increasing the stiffness. From the Fig. 4, it is seen that curing has improved the indirect tensile strength of the specimen.

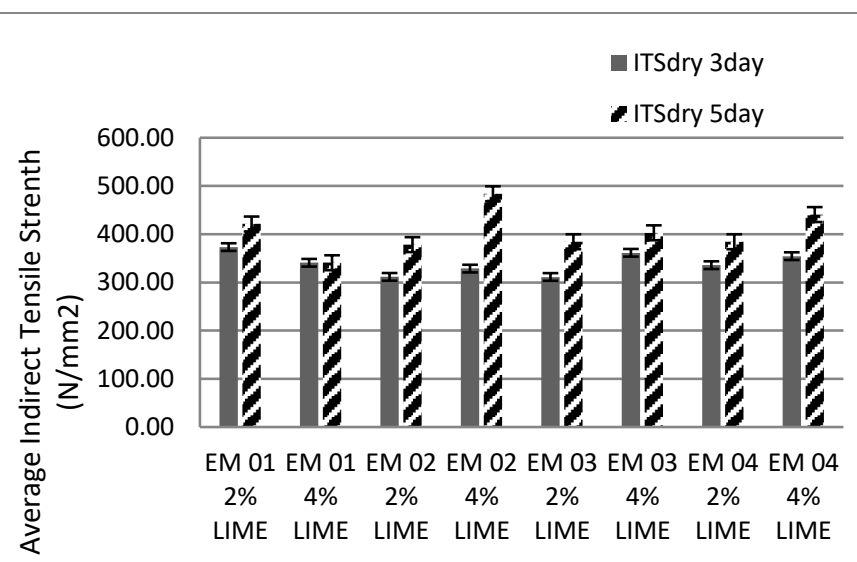

Fig. 4. Indirect tensile strength of emulsions

The strength behavior of the mix is highly dependent on the moisture and for improving the strength of the mix active

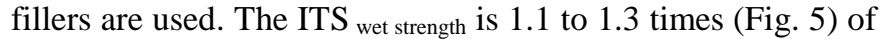
the ITS dry which is due to the active filler. Emulsion with $62 \%$ binder and $1.5 \%$ emulsifier (EM 04) is having the highest tensile strength of $500 \mathrm{kPa}$ on 3 day curing under wet condition, so in rehabilitation of pavement in moisture condition, it is preferred over the other. In 5 day curing the tensile strength of all emulsion is within the range of 400-500 $\mathrm{kPa}$. 


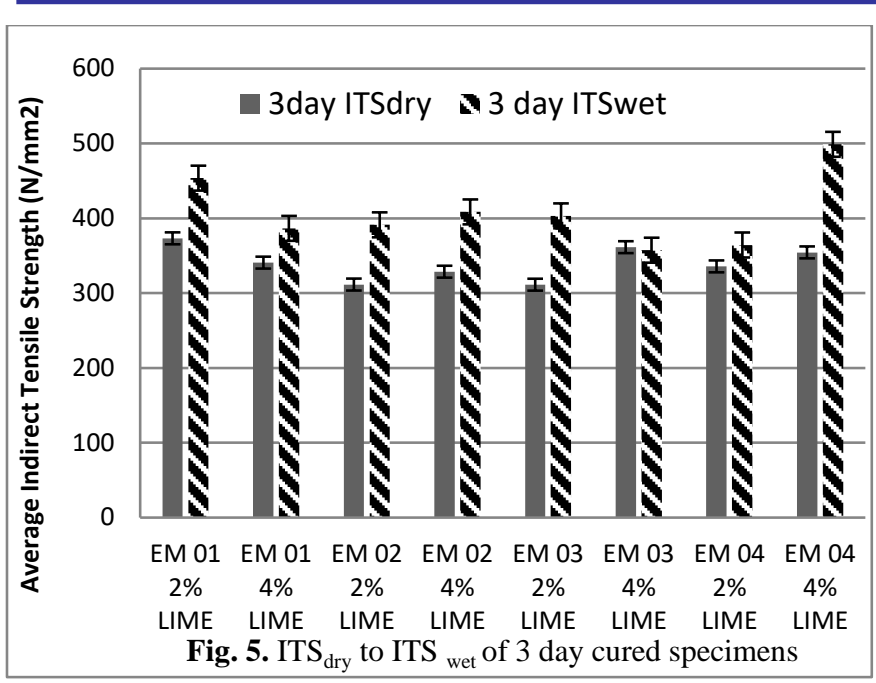

The TSR ratio is greater than 1 for all emulsion while compairing the test results. Hydrated lime (HL) is having more strength and it is preferable in mositure suscpetible regions. The ITS strength of the specmens having lime as filler showsgreater strength than specimens having Portland cement as filler, as lime increases the stiffness of the binderfines mastic mortar in order to improve the strength behavior.

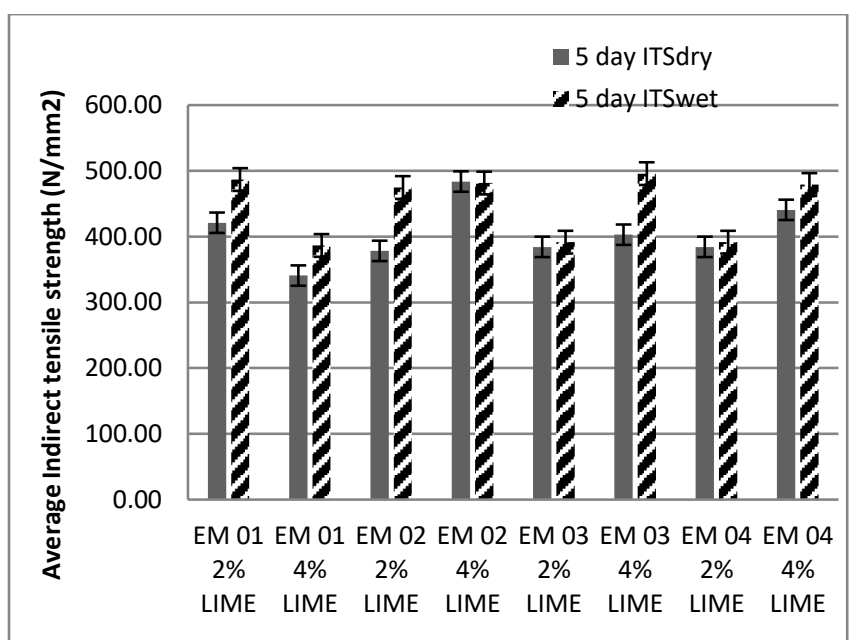

Fig. 6. ITS dry $_{\text {to }}$ ITS ${ }_{\text {wet }}$ of 5 day cured specimens

\section{DESIGN OF PAVEMENT OVERLAY}

Benkelman Beam Deflection analysis is used to evaluate the strengthening (overlay) requirement of existing flexible road pavements. Performance of flexible pavements is closely related to the elastic deflection of pavement under the wheel loads. The deformation or elastic deflection under a given load depends upon subgrade soil type, its moisture content and compaction, the thickness and quality of the pavement courses, drainage conditions, pavement surface temperature etc.

The rebound deflection values from Benkelman beam of 15 spots are obtained from a set a sample data. The mean and standard deviation was obtained. Cumulative number of standard axles was also computed from sample data.
Thickness of overlay was designed using overlay thickness design curves from IRC 81:1997.

\section{CONCLUSION}

Characterization of RAP was done in detail and its properties were studied. Aggregates were then separated from aged bitumen and its properties were tested. Then Bitumen Stabilized Material samples were cast with different emulsion, and varying parameters such as curing period and filler content. Indirect Tensile Strength of all these samples were determined to find the best combination of mix. From ITS test results, it was concluded that all mixes were BSM 1, so that it can take traffic more than 6 MSA. It was also determined that inclusion of filler alone does not justify extension in curing time. Tensile Strength Retained (TSR) was found to be greater than 0.5 always, which indicated that fillers used are effective \&even if ITS dry is greater than $400 \mathrm{kPa}$, it does not affect the performance.Design of overlay was done using IRC 81-1997.

\section{ACKNOWLEDGEMENT}

The authors are greatly indebted to Prof. Dr. J. Murali Krishnan, Department of Civil Engineering, Indian Institute of Technology, Madras and Prof. Dr. Neethu Roy, Dean R\&D, Mar Baselios College of Engineering and Technology, Trivandrum for your ultimate supports of this research.

\section{REFERENCES}

1. Gudimettla, J., Cooley, 1., and Brown, E. (2014). "Workability of hot mix asphalt", Journal of Transportation research board, Volume 1891.

2. Wimsatt, A., Estakhri, C., and Button, J.W. (2007)." A synthesis of warm mix asphalt", Journal of Transportation Engineering, 12(3), pp.18-27.

3. Sargand, S., Nazzal, M.D., and Rawashdeh, A. (2012). "Field evaluation of warm mix asphalt technology", Journal of Materials in Civil Engineering, Volume 24, Issue 11.

4. Chowdhury, A., and Button, J.W. (2008)." A review of warm mix asphalt", Texas Transportation Institute.

5. Kenneth, A., Tutu1, Yaw A., and Tuffour, M. (2016). "Warm-Mix Asphalt and Pavement Sustainability: A Review", Open Journal of Civil Engineering, Volume 6, pp. 84-93.

6. Monu, K.M., Banger, P., and Duggal, A.K. (2015). "A review paper on warm mix asphalt technologies", International Research Journal of Engineering and Technology, Volume 2, Issue 5.

7. Lewis, A.J.N., Collings, D.C. (1999). "Cold in place recycling: a relevant process for road rehabilitation and upgrading", 7th conference on asphalt pavements for Southern Africa.

8. Sebaaly, P,Bazi, G., Hitti, E.,Weitzel, D. (2004). "Performance of Cold In-Place Recycling in Nevada", Journal of the Transportation Research Board, Volume 1896.

9. Murphy, D., Emery, J. (1996). "Modified Cold In-Place Asphalt Recycling", Journal of the Transportation Research Board, Volume 1545 .

10. Taha, R.,Ali, G.,Basma, A., Al-Turk, O.,(1999)."Evaluation of Reclaimed Asphalt Pavement Aggregate in Road Bases and Subbases", Journal of the Transportation Research Board, Volume 1652.

11. Taha, R., Al-Harthy, A., Al'Shamsi, A., and Al-Zubeidi, M. (2002) "Cement Stabilization of Reclaimed Asphalt Pavement Aggregate for Road Bases and Subbases", Journal of Materials in Civil Engineering, ASCE, 14, No. 239

12. Chesner, W., Collins, R., MacKay, M., and Emery, J. (1998). "User Guidelines for Waste and By-product Materials in Pavement 
Construction," FHWA US Department of Transportation, Washington, D.C.

13. Cooley, J., and Dane, A. (2005). "Effects of Reclaimed Asphalt Pavement on Mechanical Properties of Base Materials" (Doctoral dissertation)

14. Kim, Y., Soohyok, A. M., and David, H. L. (2011). "Impacts of Curing Time and Moisture Content on Engineering Properties of Cold In-Place Recycling Mixtures Using Foamed or Emulsified Asphalt”,Journal of Materials in Civil Engineering, Volume 23, Issue 5, pp 542-553.

15. Arimilli, S., Jain, P. K., Nagabhushana, M. N. (2015) "Optimization of Recycled Asphalt Pavement in Cold Emulsified Mixtures by Mechanistic Characterization", Journal of Materials in Civil Engineering, Volume 28 (2) pp -1--1

16. Little, D. N., and Petersen, J. C. (2005) "Unique Effects of Hydrated Lime Filler on the Performance- Related Properties of Asphalt
Cements: Physical and Chemical Interactions Revisited",Journal of Materials in Civil Engineering, Volume17(2), pp 207-218.

17. Wu, S. and Qian, S. (2014). "Comparison of Warm Mix Asphalt and Hot Mix Asphalt Pavement Based On Life Cycle Assessment”, Journal of the Transportation Research Board, Volume 165(19).

18. Oner, J. and Sengoz, B. (2015). "Utilization of Recycled Asphalt Concrete with Warm Mix Asphalt and Cost-Benefit Analysis", Journal of Transportation Research Board, pp 71-79

19. Tutu, K., Tuffour, A. (2016). "Warm-Mix Asphalt and Pavement Sustainability: A Review",Open Journal of Civil Engineering Volume 06(02)

20. Choudhary, R. and Mondal. A, (2012). "Use of Cold Mixes for Rural Road Construction", International Journal of Computer Applications 